\title{
Systems of Conformational Processes
}

Korablev GA*

Doctor of Chemical Sciences, Russia

\section{Opinion}

Isomorphism as a phenomenon is usually considered as applicable to crystal structures. But, obviously, similar processes can also flow between molecular compounds, where the bond energy can be evaluated via the relative difference of electron densities of valence orbitals of interacting atoms [1]. Since P-parameter possesses wave properties (similar to $\Psi$ '-function), mainly the regularities in the interference of the corresponding waves should be fulfilled.

Oscillation weakening (in anti-phase) takes place if the difference in wave move $(\Delta)$ equals the odd number of semi-waves, it is interference minimum:

$$
\Delta=(2 n+1) \frac{\lambda}{2}=\lambda\left(n+\frac{1}{2}\right) \text { where } \mathrm{n}=0,1,2,3, \ldots
$$

The difference in wave move $(\Delta)$ for P-parameters can be evaluated via their relative value

$$
\gamma=\frac{p_{2}}{p_{1}}=\left(n+\frac{1}{2}\right)=\frac{3}{2} ; \frac{5}{2} \ldots
$$

Oscillation enhancing (in phase) takes place if the difference in wave move equals an even

${ }^{* 1}$ Corresponding author: Korablev GA, Doctor of Chemical Sciences, Professor, Izhevsk State Agricultural Academy, Russia

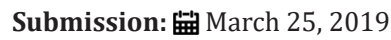

Published: 侮April 01, 2019

Volume 10 - Issue 3

How to cite this article: Korablev G. Systems of Conformational Processes. Res Dev Material Sci. 10(3).RDMS.000736.2019. DOI: $10.31031 /$ RDMS.2019.10.000736

Copyright@ Korablev GA, This article is distributed under the terms of the Creative Commons Attribution 4.0 International License, which permits unrestricted use and redistribution provided that the original author and source are credited.

$$
\Delta=2 n \frac{\lambda}{2}=\lambda n \text { or } \Delta=\lambda(n+1)(2)
$$

As applicable to P-parameters, the maximum enhance of interaction in the phase corresponds to the interactions of similarly charged systems or systems homogeneous by their properties and functions (e.g. between the fragments or blocks of complex organic structures, such as $\mathrm{CH}_{2}$ and $\mathrm{NNO}_{2}$ ).

$$
\text { And then: } \quad \gamma=\frac{P_{2}}{P_{1}}=(n+1)
$$

It was shown [2] that the molecular negativity is numerically equal to the P-parameter of the first valence electron divided by 3 . Hydrogen atom, element No 1 with orbital $1 S^{1}$ defines the main energy criteria of structural interactions (their "ancestor").

Table 1 shows its three $\mathrm{P}_{\mathrm{E}}$-parameters corresponding to three different characteristics of the atom. $R_{1}=0.5292 \mathrm{~A}^{0}$-arbital radius-quantum-mechanical characteristic gives the initial main value of $\mathrm{P}_{\mathrm{E}}$-parameter equaled to $9.0644 \mathrm{eV}$;

$\mathrm{R}_{2}=0.375 \mathrm{~A}^{0}$ - distance equaled to the half of the bond energy in $\mathrm{H}_{2}$ molecule. But if hydrogen atom is bound with other atoms, its covalent radius is $\approx 0.28 \mathrm{~A}^{0}$. It was shown earlier 5 that the condition for the formation of stable structures is an approximate equality of the P-parameter of the subsystems. Relative parameter difference is estimated by alpha factor.

In accordance with equation (2) $\mathrm{P}_{2}=\mathrm{P}_{1}(\mathrm{n}+1)$, therefore $\mathrm{P}_{1} \approx 9.0644 \mathrm{eV}, \mathrm{P}_{2} \approx 18.129 \mathrm{eV}$. These are the values of possible energy criteria of stable (stationary) structures. The dimensional characteristic $0.375 \mathrm{~A}^{\circ}$ does not satisfy them, therefore, there is a transition onto to the covalence radius $\approx 0.28 \mathrm{~A}^{\circ}$, which provides the value of P-parameter approximately equaled to $\mathrm{P}_{2}$.

It was shown earlier that the condition for the formation of stable structures is an approximate equality of the P-parameter of the subsystems. From a big number of different combinations of interactions, we can obtain series with approximately equal values of P-parameters of atoms (or radicals). Such series, by initial values of hydrogen atom, are given in Table 1 (at $\alpha<7.5 \%$ ). 
Table 1: Energy parameters of atoms and radicals.

\begin{tabular}{|c|c|c|c|c|c|c|c|c|c|c|c|}
\hline $\begin{array}{c}\text { Series } \\
\text { Number }\end{array}$ & $\mathbf{H}$ & $\mathrm{C}$ & $\mathbf{N}$ & $\mathbf{0}$ & CH & Co & NH & C-NH ${ }_{2}$ & $\mathrm{C}-\mathrm{CH}_{3}$ & $\left.<\mathrm{P}_{\mathrm{E}}\right\rangle$ & $\alpha$ \\
\hline I & $\begin{array}{c}9.0644 \\
\left(1 S^{1}\right)\end{array}$ & $\begin{array}{l}8.7582 \\
\left(2 \mathrm{P}^{1}\right) \\
9.780 \\
\left(2 \mathrm{P}^{1}\right) \\
\end{array}$ & $\begin{array}{l}9.4166 \\
\left(2 \mathrm{P}^{1}\right)\end{array}$ & $\begin{array}{l}9.7979 \\
\left(2 \mathrm{P}^{1}\right)\end{array}$ & $\begin{array}{c}9.1330 \\
\left(2 \mathrm{~S}^{2} 2 \mathrm{P}^{2}-1 \mathrm{~S}^{1}\right)\end{array}$ & $\begin{array}{c}8.4405 \\
\left(2 \mathrm{P}^{2}-2 \mathrm{P}^{2}\right)\end{array}$ & $\begin{array}{c}8.4687 \\
\left(2 \mathrm{P}^{2}-1 \mathrm{~S}^{1}\right) \\
9.1281 \\
\left(2 \mathrm{P}^{2}-1 \mathrm{~S}^{1}\right)\end{array}$ & $\begin{array}{c}8.8844 \\
2 \mathrm{~S}^{1} 2 \mathrm{P}^{1}{ }_{r}^{-} \\
\left(2 \mathrm{P}^{3}-1 \mathrm{~S}^{1}\right)\end{array}$ & $\begin{array}{c}9.2479 \\
2 \mathrm{~S}^{1} 2 \mathrm{P}_{\mathrm{r}}^{1} \\
\left(2 \mathrm{~S}^{2} 2 \mathrm{P}^{2}-\right. \\
\left.1 \mathrm{~S}^{1}\right)\end{array}$ & 9.1018 & $\begin{array}{l}0.34- \\
7.54\end{array}$ \\
\hline II & $\begin{array}{c}12.792 \\
\left(1 S^{1}\right)\end{array}$ & $\begin{array}{c}13.066 \\
\left(2 \mathrm{P}^{2}\right) \\
11.715 \\
\left(1 \mathrm{~S}^{1}\right) \\
\end{array}$ & $\begin{array}{l}11.985 \\
\left(2 \mathrm{P}^{1}\right)\end{array}$ & $\begin{array}{l}11.757 \\
\left(2 \mathrm{P}^{1}\right)\end{array}$ & $\begin{array}{c}11.679 \\
\left(2 \mathrm{~S}^{2} 2 \mathrm{P}^{2}-1 \mathrm{~S}^{1}\right) \\
12.081 \\
\left(2 \mathrm{~S}^{2} 2 \mathrm{P}^{2}-1 \mathrm{~S}^{1}\right)\end{array}$ & $\begin{array}{c}12.315 \\
\left(2 \mathrm{~S}^{2} 2 \mathrm{P}^{2-}\right. \\
\left.2 \mathrm{P}^{2}\right)\end{array}$ & $\begin{array}{c}12.632 \\
\left(2 \mathrm{~S}^{2} 2 \mathrm{P}^{3}-1 \mathrm{~S}^{1}\right)\end{array}$ & $\begin{array}{c}11.693 \\
2 \mathrm{~S}^{2} 2 \mathrm{P}^{2}- \\
\left(2 \mathrm{P}^{3}-1 \mathrm{~S}^{1}\right)\end{array}$ & $\begin{array}{c}12.181 \\
2 \mathrm{~S}^{2} 2 \mathrm{P}^{2}- \\
\left(2 \mathrm{~S}^{2} 2 \mathrm{P}^{2}-\right. \\
\left.1 \mathrm{~S}^{1}\right)\end{array}$ & 12.173 & $\begin{array}{l}0.07- \\
7.08\end{array}$ \\
\hline III & $\begin{array}{c}17.132 \\
\left(1 S^{1}\right)\end{array}$ & $\begin{array}{c}16.769 \\
\left(2 \mathrm{P}^{2}\right) \\
17.435 \\
\left(2 \mathrm{~S}^{1} 2 \mathrm{P}^{1}\right)\end{array}$ & $\begin{array}{l}16.747 \\
\left(2 \mathrm{P}^{2}\right)\end{array}$ & $\begin{array}{l}17.967 \\
\left(2 \mathrm{P}^{2}\right)\end{array}$ & $\begin{array}{l}\mathrm{C} \text { and } \mathrm{H} \\
\text { blocks }\end{array}$ & $\begin{array}{c}16.576 \\
\left(2 \mathrm{~S}^{2} 2 \mathrm{P}^{2}-\right. \\
\left.2 \mathrm{P}^{4}\right)\end{array}$ & $\mathrm{N}$ and $\mathrm{H}$ blocks & $\begin{array}{c}\mathrm{C} \text { and } \mathrm{NH}_{2} \\
\text { blocks }\end{array}$ & $\begin{array}{c}\mathrm{C} \text { and } \mathrm{NH}_{2} \\
\text { blocks }\end{array}$ & 17.104 & $\begin{array}{l}0.16- \\
4.92\end{array}$ \\
\hline
\end{tabular}

First series for $\mathrm{P}_{\mathrm{E}}=9.0644 \mathrm{eV}$-the main, initial, where $\mathrm{H}, \mathrm{C}, \mathrm{O}$, $\mathrm{N}$ basic bio structural atoms have $\mathrm{P}_{\mathrm{E}}$-parameters only of the first electron and interactions proceed in the phase. Second series for $\mathrm{P}_{\mathrm{E}}$ $=12.792 \mathrm{eV}$ is the non-rational, pathological as it more corresponds to the interactions in anti-phase: by equation (1a) $\mathrm{P}_{\mathrm{E}}=13.596 \mathrm{eV}$. Coefficient $\alpha$ between the parameters $\mathrm{P}_{\mathrm{E}}^{\prime}$ and $\mathrm{P}_{\mathrm{E}}{ }_{\mathrm{E}}$ equals $6.1 \%$, thus defining the possibility of forming "false" biostructures containing the molecular hydrogen $\mathrm{H}_{2}$. Coefficient $\alpha$ between series I and II is $34.1 \%$, thus confirming the irrationality of series II.

Third series for $\mathrm{P}_{\mathrm{E}}^{\prime}=17.132 \mathrm{eV}$ - stationary as the interactions are in the phase: by equation (1a) $\mathrm{P}_{\mathrm{E}}=18.129 \mathrm{eV}$ ( $\left.\alpha=5.5 \%\right)$. Specific local energy effects (electromagnetic fields, radiation, etc.) upon structural conformations can increasingly follow the pathological series II. Isn't it one of the reasons of normal functioning failure in biosystems, e.g., in oncological diseases? If so, some practical recommendations can be done, which come down to the necessity of converting the molecular hydrogen into the atomic one, e.g., through the interaction with hydroxyl $\mathrm{OH}$ group.

From Table 1 it is seen that the majority of atoms and radicals, depending on the bond types and bond lengths, have $\mathrm{P}_{\mathrm{E}}$-parameters of different series. When introducing the stem cells, it is important for the molecular hydrogen not to be present in their structures. Otherwise atoms and radicals can transfer into the series II and disturb the vital functions of the main first system. The reverse method can be applied to utilize polymeric materials transferring their molecular fragments into the pathological series II.

\section{Conclusion}

1. P-parameters of the first valence electron of atoms define the energy characteristics of stationary states (in normal state) under the condition of the maximum of wave processes.

Under the condition of the minimum of such interactions, the pathological (but not stationary) biostructures containing.

\section{References}

1. Korablev GA (2005) Spatial-energy principles of complex structures formation. Brill Academic Publishers and VSP, Netherlands, p. 426.

2. Korablev GA (2018) Spatial-energy interaction. Starui Oskol, TNT, Russia, p.131. 